\title{
An Investigation on Waste Tyre Rubber Treatment to Use as Aggregates in Concrete Material
}

\author{
Samaneh Pourmohammadimojaveri*, B Samali, G Adam and R Wuhrer \\ Centre for Infrastructure Engineering, Western Sydney University, Australia
}

Submission: July 20, 2017; Published: July 26, 2017

*Corresponding author: Samaneh Pourmohammadimojaveri, Centre for Infrastructure Engineering, Western Sydney University, Sydney, Australia, Email: Samaneh.pm@westernsydney.edu.au

\begin{abstract}
The amount of waste materials being accumulated globally has created a big challenge for their disposal, thus obliging the authorities to adopt measures for the use of waste materials in concrete as the use of concrete is fundamental to the booming construction industry all over the world. This is not only a cause for environmental concern, but also represents the waste of potentially useful resources. The recycled materials are a key solution in achieving sustainability that enables the earth to continue to support human life. The current research is directed toward modifying the reclaimed rubber to be suitable for another application with low consumption of energy and less impact on the environment such as chemical de-vulcanization to be used as recycled vulcanisable rubber for tyre industry and other applications.
\end{abstract}

Keywords: Component; Waste Tyre; Rubber; Chemicaly treated; Sustainability

\section{Introduction}

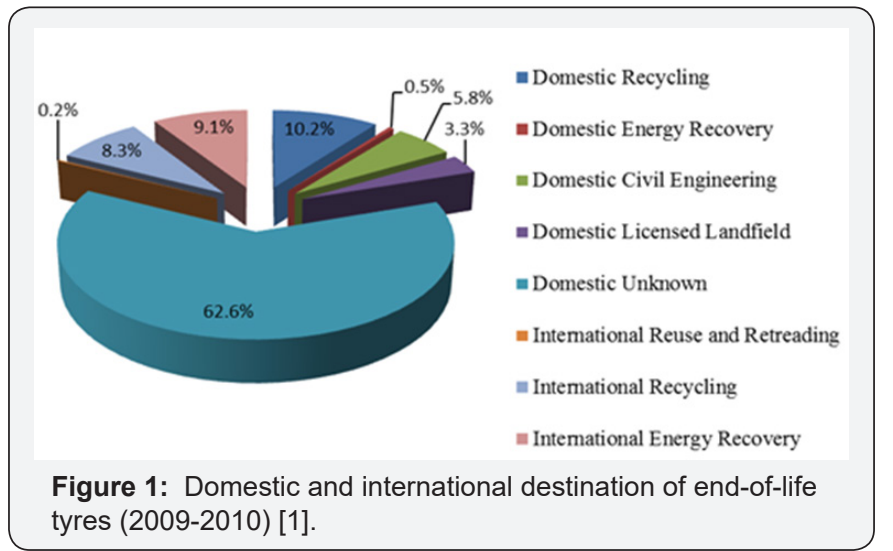

The fast development of automotive industry after the Second World War has led to the rapid accumulation of waste tyre rubber. Waste tyre rubber is extremely difficult to degrade in landfill treatment. It has been estimated that around one billion tyres are withdrawn from use in the world every year. The treatment of waste tyre rubber has recently become one of the world environmental problems. The disposal of used tyres in outdoor areas is currently an inevitable problem in most countries such as Australia. The Australian government estimates that the equivalent of 48 million passenger tyres reaches the end of their life each year and that less than $17 \%$ of waste tyres are recovered and properly managed within Australia. In the last decades, researchers have conducted many studies to compound tyre rubber with civil engineering materials, such as pavements, highway crash barriers and concretes. However, these techniques are not sufficient to fully manage the tragedy of waste tyres; therefore, the effort to find an effective solution is timely and desirable. In Figure 1, destination of end- of-life tyres in 2009-2010 has been shown.

\section{Brief Problem Statement and the Literature}

Waste tyre rubber has been stockpiled in land fields for a long time and every year a huge amount are added to this waste material. Small amount of tyre rubber waste is used as a solid fuel, which increases the polluting gases in the environment leading to diseases, poisoning the environment and fire which happen to increase the greenhouse gasses are among the undesirable consequences. Nowadays, to resolve the said problems all over the world, there are several organizations focused on manufacturing and distributing sustainable and recycled products such as recycled tyre rubber, and etc. Also there are some market leaders in delivering sustainable products to customers in Civil Infrastructure, Building and Construction, Transport and other industries. But still the problem is standing and it seems the progress is rather slow. To reduce the resulting environmental impacts is for researchers to propose new 
products considering not just the scientific benefits, but also addressing sustainable development as a major concern more than ever in their projects $[2,3]$.

The current research is based on using recycled wastes such as vulcanized rubber of used- tyres and trying to turn them into value added materials to achieve better quality. These recycled materials in some concrete applications after being modified chemically in order to obtain a product with enhanced physical, mechanical, thermal and structural properties, will decrease the impact of these waste materials on the environment. Due to high demand for concrete and its applications in all countries, the outcome of this research could make a big change in construction materials and technology for the future.

\section{Materials and Methods}

In this step of the project, rubber particles (1-4 mm size), was treated in three different chemical solutions to result in the optimized method to create surface consisting reactive functional groups such as hydroxyl, carboxyl, and/or amino, and/ or amide groups. Chemically treatment of rubber are; rubber treated with Potassium Permanganate, rubber treated with Hydrogen Peroxide and rubber treated by Sodium Hydroxide. After completing the chemical treatment, the changes on the surface of each type of rubbers studied under SEM. Figure 1 Shows the surface [1].

Figure 2(a) represents the image of untreated rubber particles showing details of the surface. Some voids are observed as predicted due to the rubber properties and its elasticity. The samples show some obvious cracks on the surface, caused by cutting and crumbling the tyre rubber during recycling process. Figure 2(b) shows treated rubber with potassium permanganate. As it is clear, the density of cracks on the surface of rubber particles, increased with treatment time. The crack size increased in depth and width as a function of activation time. Therefore, it is expected to observe an improvement in bonding between this kind of treated rubber with concrete paste.

SEM result of treated rubber with sodium hydroxide is shown in Figures 2(c). It shows that here is no obvious crack on the surface of samples, but some variation is observed on the surface of samples. Figure 2(d) shows the SEM image of treated rubber with hydrogen peroxide. As can be seen, there is no obvious crack on the surface of the samples. So it is expected to witness a decrease in compressive strength of concrete mixed with this type of treated rubber. This happened due to having less active groups to improve the bonding between treated rubber samples with hydrogen peroxide and concrete paste.

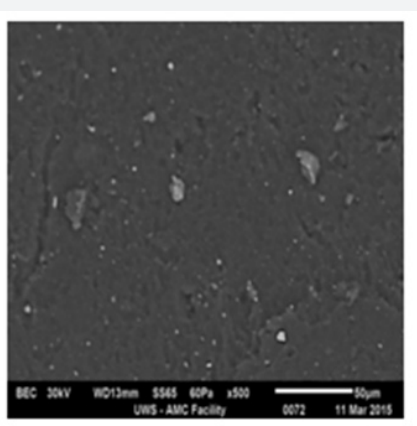

(a)

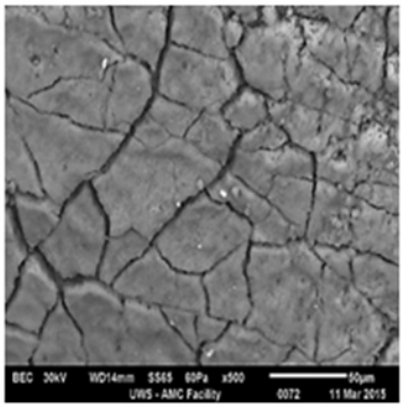

(b)

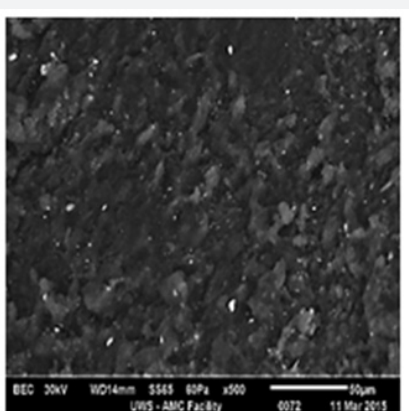

(c)

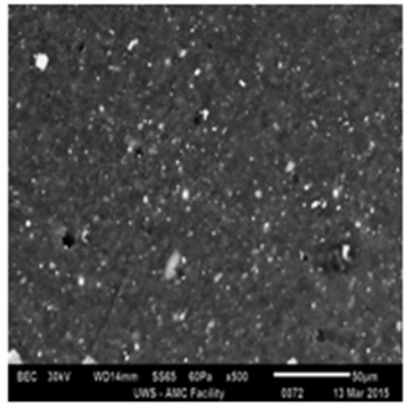

(d)

Figure 2: (a) Untreated rubber, (b) Treated rubber with Potassium permanganate, (c) Treated rubber with sodium hydroxide, (d) Treated rubber with hydrogen peroxide

\section{Conclusion}

As shown in Figure 1, treating rubber with potassium permanganate, hydrogen peroxide and sodium hydroxide was studied under microscope to investigate the surface changing during the treatment. Given the results of microstructural analysis, it is concluded that using treated rubber with potassium permanganate may be the most promising material to improve bonding in rubber concrete material compared to the untreated rubber. The mechanical properties of concrete mixtures using 
untreated and treated rubber should be studied as the future work to verify the results of microscopic characterization.

\section{References}

1. COAG Standing Council on Environment and Water. Study into domestic and international fate of end-of-life tyres, Final Report", Hyder Consulting Pty Ltd-(2012) ABN 76104485289 AA003649.

This work is licensed under Creative

Commons Attribution 4.0 License

DOI: $10.19080 / C T B E B .2017 .06 .555683$
2. Young-Chang G, Jian-Hong Z, Guang-Ming C, Zhi-Hong X (2014) Compressive behaviour of concrete structures incorporating recycled concrete aggregates, rubber crumb and reinforced with steel fibres, subjected to elevated temperatures. Journal of Cleaner Production 72 $193 \mathrm{e} 203$.

3. Fernando P, Nilomar Z, Tiago A, Adriano M (2011) Concrete made with recycled tire rubber: Effect of alkaline activation and silica fume addition. Journal of Cleaner Production 19: 757-763.

\section{Your next submission with Juniper Publishers} will reach you the below assets

- Quality Editorial service

- Swift Peer Review

- Reprints availability

- E-prints Service

- Manuscript Podcast for convenient understanding

- Global attainment for your research

- Manuscript accessibility in different formats ( Pdf, E-pub, Full Text, Audio)

- Unceasing customer service

Track the below URL for one-step submission https://juniperpublishers.com/online-submission.php 